\title{
Police confrontations among street-involved youth in a Canadian setting
}

\author{
Lianping $\mathrm{Ti}^{1}$, Evan Wood ${ }^{1,2}$, Kate Shannon ${ }^{1,2,3}$, Cindy Feng ${ }^{1}$, and Thomas Kerr ${ }^{1,2}$ \\ ${ }^{1}$ British Columbia Centre for Excellence in HIV/AIDS, St. Paul's Hospital, 608-1081 Burrard \\ Street, Vancouver, BC, Canada V6Z 1 Y6 \\ ${ }^{2}$ Department of Medicine, University of British Columbia, St. Paul's Hospital, 1081 Burrard Street, \\ Vancouver, BC, Canada V6Z 1Y6 \\ ${ }^{3}$ School of Population and Public Health, University of British Columbia, 2206 East Mall, \\ Vancouver, Canada V6T 1 Z3
}

\begin{abstract}
Background-Street-level policing has been recognized as a driver of health-related harms among people who inject drugs (IDU). However, the extent of interaction between police and street-involved youth has not been well characterized. We examined the incidence and risk factors for police confrontations among street-involved youth in a Canadian setting.

Methods-Using data derived from participants enrolled in the At-Risk Youth Study (ARYS) between 2005 and 2011, we assessed factors associated with being stopped, searched, or detained by police without arrest in the previous six months using generalized estimating equations (GEE) with logit link for binary outcomes.

Results-Among 991 participants followed during the study period, 440 (44.4\%) reported being stopped, searched, or detained by police for an incidence density of 49.20 (95\% confidence interval [CI]: 36.42-65.01) per 100 person years. In multivariate GEE analyses, factors associated with police confrontations included: male gender (adjusted odds ratio $[\mathrm{AOR}]=1.35$ ), homelessness $(\mathrm{AOR}=2.05)$, recent incarceration $(\mathrm{AOR}=1.78)$, daily cannabis use $(\mathrm{AOR}=1.31)$, daily heroin injecting $(\mathrm{AOR}=1.36)$, crack pipe/syringe sharing $(\mathrm{AOR}=1.61)$, injection drug use ( $A O R=1.37)$, public drug use $(\mathrm{AOR}=2.19)$, sex work involvement $(\mathrm{AOR}=1.67)$, and drug dealing (AOR $=1.49$ ) (all $\mathrm{p}<0.05)$. In total, $19.0 \%$ of participants reported that police confiscated their drug paraphernalia without arresting them. Additionally, $16.9 \%$ individuals reported experiencing violence at the hands of police.
\end{abstract}

Conclusion-We found that various factors, such as homelessness and markers of more severe addiction, increased the likelihood of being confronted by police, and police confrontations were associated with markers of health-related harm among street youth. These findings highlight the need for social and structural interventions that best enable police to fulfill public safety and public order objectives without negatively influencing health behaviours of street youth.

\footnotetext{
(c) 2012 Elsevier B.V. All rights reserved.

Send correspondence to: Thomas Kerr, PhD, Director, Urban Health Research Initiative, BC Centre for Excellence in HIV/AIDS, 608 - 1081 Burrard Street, Vancouver BC V6Z 1Y6, Canada, Tel: 604-806-9116, Fax: 604-806-9044, uhri-tk@ cfenet.ubc.ca.

Conflict of interests: None.

Publisher's Disclaimer: This is a PDF file of an unedited manuscript that has been accepted for publication. As a service to our customers we are providing this early version of the manuscript. The manuscript will undergo copyediting, typesetting, and review of the resulting proof before it is published in its final citable form. Please note that during the production process errors may be discovered which could affect the content, and all legal disclaimers that apply to the journal pertain.
} 


\section{Keywords}

street-involved youth; policing; Vancouver; illicit drug use

\section{INTRODUCTION}

Illicit drug markets remain a major public order concern in many urban areas worldwide. In response to the ongoing problems related to substance use in Canada, the federal government launched a 'National Anti-Drug Strategy' in October 2007, which focuses heavily on law enforcement techniques as a means of reducing the supply and use of illicit drugs, and the associated public order impacts (Office of the Prime Minister, 2007). Although law enforcement represents the dominant approach to addressing illicit drug use (Dauvergne, 2009; Wood \& Kerr, 2005), several studies have documented the unintended negative consequences associated with intensified enforcement approaches within drug markets among people who inject drugs (IDU) and sex workers (Shannon et al., 2008; Small, Kerr, Charette, Schechter, \& Spittal, 2006; Werb, Wood, et al., 2008). Specifically, police crackdowns within drug and sex work markets have been associated with an unwillingness to obtain and carry sterile syringes and condoms (Chakrapani, Newman, Shunmugam, \& Dubrow, 2011; Cooper, Moore, Gruskin, \& Krieger, 2005), syringe sharing (Rhodes et al., 2004), reductions in access to health and harm reduction services (Mimiaga et al., 2010; Small et al., 2006), and violence (Shannon et al., 2009; Werb, Rowell, Kerr, Montaner, \& Wood, 2011).

Rhodes' Risk Environment Framework has been applied extensively to identify the role that social, structural and environmental factors operating within drug markets play in shaping risk among IDU, and has further helped elucidate how policing interventions can function as social-structural drivers of adverse health outcomes within this population (Rhodes, 2002; Rhodes, Singer, Bourgois, Friedman, \& Strathdee, 2005). While the impact of police confrontations on adult IDU has been described previously (Aitken, Moore, Higgs, Kelsall, \& Kerger, 2002; Werb, Wood, et al., 2008), less is known about interactions between police and street-involved drug using youth in a Canadian setting. As well, little attention has been paid to how contextual conditions elevate risk for confrontations with police. Therefore, applying a Risk Environment perspective, we undertook the present study to examine the prevalence of and factors associated with being stopped, searched, or detained by police without arrest among street-involved youth in Vancouver, Canada. As well, given concerns regarding the potential of police to interfere with HIV prevention efforts (Werb, Wood, et al., 2008), we sought to assess the prevalence of police confiscation of sterile syringes and other drug paraphernalia. Lastly, given persistent concerns regarding drug law enforcement and violence (Marshall, Fairbairn, Li, Wood, \& Kerr, 2008; Shannon et al., 2008) we also sought to assess the prevalence of violent interactions involving police.

\section{METHODS}

The At-Risk Youth Study (ARYS) is an ongoing prospective cohort study of street-involved youth in Vancouver. This study has been described in detail previously (Wood, Stoltz, Montaner, \& Kerr, 2006). In brief, snowball sampling and extensive street-based outreach were conducted to recruit participants into the study. The term "street-involved youth" has been defined as a young person who spends a substantial amount of time on the street or who is heavily engaged in the street economy (Marlatt, 2002), and may include youth who are absolutely, periodically, or at imminent risk of being homeless (Daly, 1996). Persons were eligible for the study if they were between 14 and 26 years of age, had used illicit drugs other than or in addition to marijuana in the past 30 days and provided informed 
consent. At baseline and semi-annually thereafter, participants complete an intervieweradministered questionnaire and provide blood samples for HIV and hepatitis C (HCV) serology. The questionnaire elicits socio-demographic data as well as information regarding participants' drug use and other behavioural and economic data such as sex work involvement, income generation sources, housing, incarceration experiences, and encounters with police. All participants receive a monetary stipend of $\$ 20 \mathrm{CDN}$ after each visit. The study has been approved by the University of British Columbia/Providence Health Care Research Ethics Board.

All participants who completed a baseline survey and were seen for study follow-up between December 2005 and November 2011 were included in the study. For the present analyses, the primary outcome of interest was having reported being 'jacked up' (i.e. stopped, searched or detained without arrest) by police in the previous six months. We focused on non-arrest events since less is known about the factors associated with this form of police interaction compared to events that end in arrest and incarceration. Further, previous analyses focused on adult IDU have pointed to the harms associated with this form of police activity (Werb, Wood, et al., 2008). Independent variables in this analysis included an array of socio-demographic and behavioural characteristics, as well as, consistent with the Risk Environment Framework, we considered variables reflective of social, structural, and environmental conditions, including: age (per year older), gender (female vs. male), Aboriginal ancestry (yes vs. no), current homelessness (yes vs. no), recent incarceration (yes vs. no), daily cannabis use (yes vs. no), daily crack use (yes vs. no), daily crystal methamphetamine use (yes vs. no), daily heroin injecting (yes vs. no), overdose (yes vs. no), shared crack pipes and/or syringes (yes vs. no), any injection drug use (yes vs. no), binge drug use (yes vs. no), public drug use (yes vs. no), sex work involvement (yes vs. no), and drug dealing (yes vs. no). Unless otherwise indicated, all variables refer to activities in the previous six months. Participants were defined as homeless if they reported currently living on the street or having no fixed address.

Univariate and multivariate statistics were used to identify factors associated with being 'jacked up'. We also calculated the incidence density of being 'jacked up' by police among participants by dividing the number of new events (i.e. participants reporting new events of being 'jacked up') by the person-years of the at-risk population. Since analyses of factors potentially associated with our outcome of interest included serial measures for each subject, we used generalized estimating equations (GEE) for binary outcomes with logit link for the analysis of correlated data to determine factors associated with being stopped, searched, or detained by police without arrest. These methods provided standard errors adjusted by multiple observations per person using an exchangeable correlation structure. Therefore, data from every participant follow-up visit were considered in this analysis. As a first step, GEE univariate analyses were conducted to obtain unadjusted odds ratios and 95\% confidence intervals for variables of interest. The multivariate model was then fit using -an a priori-defined statistical protocol based on examination of the quasi-likelihood under the independence model criterion (QIC) for GEE and $p$-values (Pan, 2001). First, a preliminary model was constructed including all variables significant in bivariate analysis at $p<0.05$. Following this, each variable with the highest $p$-value was removed sequentially, with the final model including the set of variables associated with the lowest QIC. As a subanalysis, participants were asked to report whether police ever confiscated their drug paraphernalia (e.g., sterile syringes, crack pipes) without arresting them. Additionally, we asked participants to report whether they had experienced violence at the hands of police in the past six months. More specifically, of the participants who reported "yes" to having been attacked, assaulted (including sexual assault), or suffered any kind of violence in the last six months, those who responded "yes" to ever being attacked by police were considered as 
having experienced what they believed to be violence at the hands of police. All statistical analyses were performed using SAS software version 9.1. All $p$-values are two-sided.

\section{RESULTS}

Of the 991 participants eligible for the present analysis, 310 (31.3\%) were female and the median age at baseline was 19.8 years (interquartile range $[\mathrm{IQR}\}=21.9-23.7$ ). In total, $23.6 \%$ were of Aboriginal ancestry, and $36.4 \%$ and $38.6 \%$ reported homelessness and injection drug use at baseline, respectively. These participants contributed to a total of 2,939 observations during the follow-up period. Of these individuals, 344 participants (34.7\%) reported being 'jacked up' in the previous six months at baseline and a total of 440 participants (44.4\%) reported being 'jacked up' during the 72-month study period for an incidence density of 49.20 (95\% confidence interval [CI]: 36.42-65.01) per 100 person years.

Table 1 shows the results of the bivariate and multivariate GEE analyses of factors associated with being stopped, searched, or detained by police without arrest in the last six months. In bivariate GEE logistic analyses, being 'jacked up' was significantly associated with: male gender (odds ratio [OR] $=1.47 ; 95 \%$ CI: $1.16-1.87$ ), current homelessness $(\mathrm{OR}=$ 2.59; 95\%CI: $2.14-3.15)$, recent incarceration ( $\mathrm{OR}=2.13$; 95\%CI: $1.73-2.63)$, daily cannabis use (OR $=1.59 ; 95 \% \mathrm{CI}: 1.24-2.04)$, daily crack use (OR $=1.72 ; 95 \% \mathrm{CI}: 1.44$ $2.04)$, daily crystal methamphetamine use $(\mathrm{OR}=1.64 ; 95 \% \mathrm{CI}: 1.38-1.95)$, daily heroin injecting (OR $=1.92$; 95\% CI: $1.55-2.39)$, overdose (OR $=1.30$; 95\%CI: $1.00-1.69)$, crack pipe and/or syringe sharing $(\mathrm{OR}=2.20 ; 95 \% \mathrm{CI}: 1.84-2.63)$, any injection drug use $(\mathrm{OR}=$ 2.02 ; 95\%CI: $1.67-2.45)$, binge drug use $(\mathrm{OR}=1.57$; 95\%CI: $1.33-1.87)$, public drug use $(\mathrm{OR}=2.45 ; 95 \% \mathrm{CI}: 1.36-4.41)$, sex work involvement $(\mathrm{OR}=2.02 ; 95 \% \mathrm{CI}: 1.50-2.73)$, and drug dealing $(\mathrm{OR}=1.90 ; 95 \% \mathrm{CI}$ : $1.59-2.27)$.

In multivariate GEE analyses, factors that remained significantly associated with being stopped, searched, or detained by police without arrest included: male gender (adjusted odds ratio $[\mathrm{AOR}]=1.35 ; 95 \% \mathrm{CI}: 1.05-1.73)$, homelessness $(\mathrm{AOR}=2.05 ; 95 \% \mathrm{CI}: 1.67-2.52$ ), recent incarceration $(\mathrm{AOR}=1.78 ; 95 \% \mathrm{CI}: 1.42-2.24)$, daily cannabis use $(\mathrm{AOR}=1.31$; 95\%CI: $1.02-1.68$ ), daily heroin injecting (AOR $=1.36$; 95\% CI: $1.03-1.79$ ), crack pipe/ syringe sharing $(\mathrm{AOR}=1.61 ; 95 \% \mathrm{CI}: 1.33-1.95)$, any injection drug use $(\mathrm{AOR}=1.37$; 95\% CI: $1.07-1.76)$, public drug use (AOR $=2.19 ; 95 \%$ CI: $1.22-3.90)$, sex work involvement $(\mathrm{AOR}=1.67 ; 95 \% \mathrm{CI}: 1.20-2.33)$, and drug dealing $(\mathrm{AOR}=1.49 ; 95 \% \mathrm{CI}$ : 1.24-1.80). Of the 991 participants included in this study, 188 (19.0\%) unique individuals reported that police took away their drug paraphernalia without arresting them at some point during the study period. Additionally, 167 (16.9\%) of participants reported experiencing violence at the hands of police at some point during the study period.

\section{DISCUSSION}

During the study period, a high proportion (44.4\%) of our study sample reported being stopped, searched, or detained by police without arrest in the last six months. Variables significantly and independently associated with this form of police confrontation included a diverse set of individual and contextual factors, including: male gender, homelessness, recent incarceration, daily cannabis use, daily heroin injecting, crack pipe/syringe sharing, any injecting, public drug use, sex work involvement, and drug dealing. We also found that during the study period, almost one-fifth (19.0\%) of the sample reported that police confiscated their drug paraphernalia without arresting them and $16.9 \%$ reported experiencing what they believed to be violence by police without arrest in the previous six months. 
Of particular concern is the finding that approximately one-fifth of individuals reported having their drug paraphernalia (e.g. syringes, pipes) confiscated by police without any arrest. While it is encouraging that Vancouver has an established sterile drug paraphernalia distribution program and there is widespread access to this type of service, it is possible that confiscation of sterile drug paraphernalia by police may promote high-risk behaviours (i.e., syringe sharing) and vulnerability to disease transmission among this subpopulation. This is consistent with findings from a similar study involving adult IDU, which found that among those who had their syringes confiscated, several reported immediately borrowing a used syringe (Werb, Wood, et al., 2008). Our study also revealed that $16.9 \%$ of participants experienced what they perceived to be violence at the hands of police in the previous six months, indicating that street-level policing is a contributing factor to experiences of violence among street-involved youth. Consistent with previous reports of police violence directed at highly marginalized populations in the downtown eastside of Vancouver (DTES), the fear of police harassment and violence has consequentially prevented many individuals from accessing health and harm reduction services (Human Rights Watch, 2003; Pivot Legal Society, 2004). Therefore, reforms to policing practices are needed to ensure that police actions do not undermine public health efforts, including those focused on preventing the transmission of infectious diseases (Chakrapani et al., 2011). Partnering public health and public order objectives with policing strategies may have success in minimizing negative health consequences among street-involved youth (DeBeck et al., 2008).

Our findings are consistent with a previous study showing high rates of police confrontation among adult IDU in the DTES (Werb, Wood, et al., 2008), with male youth being more likely to experience police confrontation compared to female youth. This gender difference may be due to the fact that a larger proportion of male street-involved youth report prior injection drug use and other high-risk behaviours (DeMatteo et al., 1999; Kerr, Marshall, et al., 2009), and are overrepresented in the criminal justice system (Public Health Agency of Canada, 2006). Our study also revealed that recently incarcerated youth were significantly and positively associated with being stopped, searched, or detained by police without arrest. This may also reflect previous involvement with the criminal justice system, as youth who hold criminal records may be more likely to be known to police (Cohen \& Amon, 2008). Moreover, street-involved youth who have been recently incarcerated are also more vulnerable to recidivism (Cottle, Lee, \& Heilbrun, 2001; Dunnet, 2008; Myner, Santman, Cappelletty, \& Perlmutter, 1998), thereby making them highly susceptible to future police confrontation. Interventions to address the underlying causes of crime among youth, such as improving the socio-economic status of the subpopulation by providing stable housing and low-threshold employment opportunities, and by providing access to voluntary drug and alcohol addiction treatment, may have potential to reduce recidivism in this setting (Greenwood, 2011; United Nations, 2004). As well, given the known harms associated with incarceration (McReynolds \& Wasserman, 2011; Milloy et al., 2008), efforts should be made to divert street-youth away from correctional environments and into treatment programs.

Several drug use behaviours were found to be associated with being stopped, searched or detained by police without arrest. Our finding indicating that street-involved youth who use cannabis daily were more likely to experience confrontations with police may reflect the fact that smoking cannabis produces visible smoke as well as a distinct scent that may be easily identified by police. Other visible drug use behaviours found to be linked with police confrontation included daily heroin injecting and injection drug use. The visible act of preparing and injecting drugs, as well as the presence of drug paraphernalia on their person, marks an individual as a drug user and consequently, that individual may be more likely to be confronted by police (Cooper et al., 2005; Rhodes et al., 2006). That sharing of smoking and/or injecting paraphernalia was also independently and significantly associated with 
being stopped, searched, or detained by police without arrest is of particular concern. Given that previous research has demonstrated that sharing of crack pipes and syringes is linked to difficulty accessing drug paraphernalia (Kerr, Fairbairn, et al., 2009; Ti et al., 2011), and fear of police confrontation prevent many individuals from accessing harm reduction distribution sites (Rhodes et al., 2006), it is possible that this high risk behaviour may be intensified due to these circumstances. Improving access to drug paraphernalia by extending operation hours of distribution sites and increasing mobile and outreach resources may have potential for success in this setting. As well, police could be encouraged to avoid positioning themselves close to outlets that distribute drug use paraphernalia, as this may discourage access among vulnerable populations.

Of particular concern is that the present study found sex work involvement to be a strong predictor of being stopped, searched, or detained by police without arrest. Within a highly criminalized sex work environment, this association supports a growing body of evidence of the structural conditions that render street-involved sex workers particularly vulnerable to adversarial interactions with police (Maher \& Dixon, 1999; Shannon et al., 2008).

Specifically, in Canada, criminalized laws such as the Bawdy House provision that prohibit sex workers from working in managed or cooperative indoor environments (e.g. brothels) leave the most marginalized sex workers with little option but to engage potential clients in public settings, thus making them more visible to police (Vancouver Sun, 2010; Zerbisias, 2010). This finding is of concern given past evidence indicating that among female sex workers in Vancouver, displacement due to enforcement pressure is associated with disruptions in access to HIV prevention materials such as condoms and sterile syringes, particularly among youth (Shannon et al., 2008). Accordingly, structural interventions aimed at amending Canada's criminalized sex work laws are needed to reduce negative confrontations with police among sex workers and promote access to HIV prevention tools among sex workers. Although a recent court case in Ontario struck down the laws prohibiting bawdy houses, communicating laws, which disproportionally affects street-level sex workers, was upheld (BBC News, 2012; Nixon, 2012). Communicating laws refers to laws that restrict soliciting in public for the purpose of prostitution (Pivot Legal Society, 2004). Advocates continue to express concern for the safety of street-level sex workers given that this highly marginalized subpopulation will remain vulnerable to abuse, violence, and confrontations with police (Duffy, Singer, \& Ionova, 2012; Fournier, 2012). Further, this decision is expected to be appealed by the federal government of Canada and therefore it is uncertain whether the recent decision in Ontario will hold (Postmedia News, 2012).

Our findings also indicated that drug dealing was independently associated with reports of police confrontations. This is consistent with previous studies demonstrating that streetinvolved youth continue to be involved in high-risk income generating activities common within drug markets as a means to support their drug use behaviour and basic survival needs (Kerr, Marshall, et al., 2009; O'Grady \& Gaetz, 2004). However, a study in Vancouver indicated that almost half of IDU involved in these income-generating activities were willing to engage in alternative, low-threshold employment if given the opportunity (DeBeck et al., 2011). Prior research has demonstrated that social factors such as poverty, unstable housing, and drug dependence are drivers of youth participation in high-income generating activities (Chettiar, Shannon, Wood, Zhang, \& Kerr, 2010; Lankenau, Clatts, Welle, Goldsamt, \& Gwadz, 2005; Werb, Kerr, Li, Montaner, \& Wood, 2008). Therefore, in order to reduce engagement in illegal income generation activities associated with the drug market (e.g. drug dealing) among street-involved youth, and thereby minimize police confrontations in this setting, structural interventions that focus on providing alternative low-threshold employment opportunities for street-involved youth are needed. 
Consistent with previous studies indicating a significant association between homelessness and policing among adult IDU (Volkmann et al., 2011), we found that street-involved youth who reported being homeless at some point during the study period were also highly vulnerable to street-level policing. This may reflect the fact that they are more likely to spend time on the street and be immersed in drug markets and related activities compared to youth who do not report homelessness (Mastro, Cunningham, Medrano, \& van Dam, 2012). We also found that public drug use was independently associated with being stopped, searched, or detained by police without any arrest. Those who engage in public drug use are vulnerable to police confrontations by virtue of the fact that they are more likely to be seen consuming drugs or being intoxicated within public settings (Small, Rhodes, Wood, \& Kerr, 2007). Considering the high prevalence of homelessness and public drug use among streetinvolved youth (DeMatteo et al., 1999; Marshall, Kerr, Qi, Montaner, \& Wood, 2010; Rachlis, Wood, Zhang, Montaner, \& Kerr, 2009), additional efforts to address these environmental determinants of risk among this subpopulation may be of greater benefit than efforts that focus solely on modifying individual behaviour. These include structural and environmental interventions that have demonstrated effectiveness in reducing harm and risk among youth and adult drug users, including the provision of stable housing opportunities, the establishment of supervised injection facilities, and improved access to drug and alcohol treatment centres (Frankish, Hwang, \& Quantz, 2005; Hadland, Kerr, Li, Montaner, \& Wood, 2009; Hillis et al., 2012; Stoltz et al., 2007).

Our study has several important limitations. Firstly, ARYS is not a random sample of streetinvolved youth, and therefore may not be generalizable to other settings (Wood et al., 2006). Secondly, given that this study relied primarily on self-report, we may have underestimated socially undesirable behaviours such as drug dealing and sex work involvement (Des Jarlais et al., 1999). In addition, it may be difficult to assess whether police confrontations experienced by street-involved youth was legally justified or excessive based on selfreported data. Lastly, the statistical methods used in our study only examine characteristics that co-occur with being stopped, searched, or detained by police without arrest. Further research examining these temporal dynamics would be required to understand the causal relationships between being police confrontations and the factors considered herein.

In summary, we found that over a third of street involved youth in our cohort reported being stopped, searched, or detained by police without any arrest. Our findings revealed that these individuals were more likely to be male, homeless, recently incarcerated, sex workers, and a daily user of cannabis or heroin injector. They were also more likely to report crack pipe/ syringe sharing, public drug use, and drug dealing. These analyses suggest that various individual and contextual factors elevate risk for confrontations with police among streetinvolved youth. Given that many participants in this study reported that police had confiscated their sterile drug use paraphernalia, and that many had been subject to perceived violence by police, these findings further suggest that policing is contributing to the socialstructural production of harm among street-involved youth in Vancouver. Although some degree of law enforcement presence is needed in some situations involving street-youth (e.g., in the case that street-youth are presented as a risk to themselves or to others), our findings point to the need for various social and structural interventions, as well as interventions that better harmonize policing and public health efforts.

\section{Acknowledgments}

The authors thank the study participants for their contribution to the research, as well as current and past researchers and staff. We would specifically like to thank Deborah Graham, Peter Vann, Caitlin Johnston, Steve Kain, and Calvin Lai for their research and administrative assistance. The study was supported by the US National Institutes of Health (R01DA028532) and the Canadian Institutes of Health Research (MOP 102742). Thomas Kerr 
and Kate Shannon are supported by the Michael Smith Foundation for Health Research. Kate Shannon is also supported by CIHR and US NIH.

\section{References}

Aitken C, Moore D, Higgs P, Kelsall J, Kerger M. The impact of a police crackdown on a street drug scene: evidence from the street. International Journal of Drug Policy. 2002; 13:193-202.

BBC News. Ontario brothel ban quashed by appeal court. BBC News; 2012 Mar 26. Retrieved from http://www.bbc.co.uk/news/world-us-canada-17520140

Chakrapani V, Newman P, Shunmugam M, Dubrow R. Social-structural contexts of needle and syringe sharing behaviours of HIV-positive injecting drug users in Manipur, India: a mixed methods investigation. Harm Reduction Journal. 2011; 8(9)

Chettiar J, Shannon K, Wood E, Zhang R, Kerr T. Survival sex work involvement among streetinvolved youth who use drugs in a Canadian setting. Journal of Public Health. 2010; 32(3):322-327. [PubMed: 20061578]

Cohen J, Amon J. Health and Human Rights Concerns of Drug Users in Detention in Guangxi Province, China. PLoS Medicine. 2008; 5(12):e234. [PubMed: 19071954]

Cooper H, Moore L, Gruskin S, Krieger N. The impact of a police drug crackdown on drug injectors' ability to practice harm reduction: A qualitative study. Social Science and Medicine. 2005; 61:673684. [PubMed: 15899325]

Cottle C, Lee R, Heilbrun K. The Prediction of Criminal Recidivism in Juveniles: A Meta-Analysis. Criminal Justice and Behavior. 2001; 28:367-394.

Daly, G. Homeless: Policies, Strategies, and Lives on the Street. London: Routledge; 1996.

Dauvergne, M. Trends in police-reported drug offences in Canada. Statistics Canada; 2009.

DeBeck K, Wood E, Qi J, Fu E, McArthur D, Montaner J, Kerr T. Interest in low-threshold employment among people who inject illicit drugs: implications for street disorder. International Journal of Drug Policy. 2011; 22(5):376-384. [PubMed: 21684142]

DeBeck K, Wood E, Zhang R, Tyndall M, Montaner J, Kerr T. Police and public health partnerships: Evidence from the evaluation of Vancouver's supervised injection facility. Substance Abuse Treatment, Prevention and Policy. 2008; 3(11)

DeMatteo D, Major C, Block B, Coates R, Fearon M, Goldberg E, King S, et al. Toronto Street Youth and HIV/AIDS: Prevalence, Demographics, and Risk. Journal of Adolescent Health. 1999; 25:358-366. [PubMed: 10551667]

Des Jarlais D, Paone D, Milliken J, Turner C, Miller H, Gribble J, Shi Q, et al. Audio-computer interviewing to measure risk behaviour for HIV among injecting drug users: a quasi-randomised trial. Lancet. 1999; 353:1657-1661. [PubMed: 10335785]

Duffy, A.; Singer, Z.; Ionova, M. Sex workers see little change here. Ottawa Citizen; 2012 Mar 27. Retrieved from http://www.ottawacitizen.com/news/workers+little+change+here/6363135/ story.html

Dunnet, A. The Cedar Project: Vulnerability to Recidivism Among Aboriginal Young People Who Use Drugs. Simon Fraser University; Vancouver: 2008.

Fournier, S. Ontario prostitution ruling leaves street sex workers at risk: advocates. The Province. 2012 Mar 26. Retrieved from http://www.theprovince.com/news/Ontario+prostitution+ruling+leaves +street+workers+risk+advocates/6361985/story.html

Frankish C, Hwang S, Quantz D. Homelessness and Health in Canada. Canadian Journal of Public Health. 2005; 96:S23-S29.

Greenwood, P. Preventing and Reducing Youth Crime and Violence: Using Evidence-Based Practices. Sacramento: Governor's Office of Gang and Youth Violence Policy; 2011.

Hadland S, Kerr T, Li K, Montaner J, Wood E. Access to drug and alcohol treatment among a cohort of street-involved youth. Drug and Alcohol Dependence. 2009; 101(1-2):1-7. [PubMed: 19081203]

Hillis S, Zapata L, Robbins C, Kissin D, Skipalska H, Yorick R, Finnerty E, et al. HIV seroprevalence among orphaned and homeless youth: no place like home. AIDS. 2012; 26(1):105-110. [PubMed: 21881479] 
Human Rights Watch. Abusing the Abuser: Police Misconduct, Harm Reduction, and HIV/AIDS in Vancouver ( No 15: 2(B)). New York: Human Rights Watch; 2003. Retrieved from http:// www.hrw.org/reports/2003/canada/canada0503.pdf

Kerr T, Fairbairn N, Hayashi K, Suwannawong P, Kaplan K, Zhang R, Wood E. Difficulty accessing syringes and syringe borrowing among injection drug users in Bangkok, Thailand. Drug Alcohol Rev. 2009; 29:157-161. [PubMed: 20447223]

Kerr T, Marshall B, Miller C, Shannon K, Zhang R, Montaner J, Wood E. Injection drug use among street-involved youth in a Canadian setting. BMC Public Health. 2009; 9(171)

Lankenau S, Clatts M, Welle D, Goldsamt L, Gwadz M. Street careers: homelessness, drug use, and sex work among young men who have sex with men (YMSM). International Journal of Drug Policy. 2005; 16:10-18. [PubMed: 18185845]

Maher L, Dixon D. Policing and public health: Law enforcement and harm minimization in a streetlevel drug market. British Journal of Criminology. 1999; 39(4):488-512.

Marlatt, G. Harm Reduction: Pragmatic Strategies for Managing High-Risk Behaviors. New York: The Guilford Press; 2002.

Marshall B, Fairbairn N, Li K, Wood E, Kerr T. Physical violence among a prospective cohort of injection drug users: A gender-focused approach. Drug and Alcohol Dependence. 2008; 97:237_ 246. [PubMed: 18487025]

Marshall B, Kerr T, Qi J, Montaner J, Wood E. Public injecting and HIV risk behaviour among streetinvolved youth. Drug and Alcohol Dependence. 2010; 110:254-258. [PubMed: 20456875]

Mastro T, Cunningham J, Medrano T, van Dam J. Youth and HIV: the intersection of homelessness, orphaned status, injection drug use and sexual risk. AIDS. 2012; 26:111-113. [PubMed: 22126814]

McReynolds L, Wasserman G. Self-injury in incarcerated juvenile females: Contributions of mental health and traumatic experiences. Journal of Traumatic Stress. 2011; 24(6):752-755. [PubMed: 22113950]

Milloy M, Wood E, Small W, Tyndall M, Lai C, Montaner J, Kerr T. Incarceration experiences in a cohort of active injection drug users. Drug and Alcohol Review. 2008:1-7.

Mimiaga M, Safren S, Dvoryak S, Reisner S, Needle R, Woody G. We fear the police, and the police fear us : structural and individual barriers and facilitators to HIV medication adherence among injection drug users in Kiev, Ukraine. AIDS Care. 2010; 22(11):1305-1313. [PubMed: 20640954]

Myner J, Santman J, Cappelletty G, Perlmutter B. Variables Related to Recidivism Among Juvenile Offenders. International Journal of Offender Therapy and Comparative Criminology. 1998; 42:6580.

Nixon, G. Ontario Appeal Court strikes down ban on brothels. CBC News; 2012 Mar 26. Retrieved from http://www.cbc.ca/news/canada/story/2012/03/26/ontario-appeal-court-sex-trade-lawsmonday.html

O’Grady B, Gaetz S. Homelessness, Gender and Subsistence: The Case of Toronto Street Youth. Journal of Youth Studies. 2004; 7(4):397-416.

Office of the Prime Minister. Speech October 4, 2007: Prime Minister pledges crackdown on drug criminals, compassion for their victims. Government of Canada; 2007. Retrieved from : http:// news.gc.ca/web/view/en/index.jsp?articleid $=352609 \&$

Pan W. Akaike's Information Criterion in Generalized Estimating Equations. Biometrics. 2001; 57(1): 120-125. [PubMed: 11252586]

Pivot Legal Society. Voices for Dignity: A Call to End the Harms Caused by Canada's Sex Trade Laws. Vancouver: Pivot Legal Society; 2004. Retrieved from http://www.pivotlegal.org/sites/ pivotlegal.org/files/voicesfordignity.pdf

Postmedia News. Feds to review legal options following prostitution court ruling. The Vancouver Sun. 2012 Mar 26. Retrieved from http://www.vancouversun.com/news/Feds+review+legal+options +following+prostitution+court+ruling/6360636/story.html

Public Health Agency of Canada. Street Youth in Canada: Findings from Enhanced Surveillance of Canadian Street Youth, 1999-2003. Public Health Agency of Canada; 2006. Retrieved from http:// www.phac-aspc.gc.ca/std-mts/reports_06/pdf/street_youth_e.pdf 
Rachlis B, Wood E, Zhang R, Montaner J, Kerr T. High rates of homelessness among a cohort of street-involved youth. Health Place. 2009; 15(1):10-17. [PubMed: 18358759]

Rhodes T. The risk environment : a framework for understanding and reducing drug-related harm. International Journal of Drug Policy. 2002; 13:85-94.

Rhodes T, Judd A, Mikhailova L, Sarang A, Khutorskoy M, Platt L, Lowndes C, et al. Injecting Equipment Sharing Among Injecting Drug Users in Togliatti City, Russian Federation: Maximizing the Protective Effects of Syringe Distribution. Journal of Acquired Immune Deficiency Syndromes. 2004; 35:293-300. [PubMed: 15076245]

Rhodes T, Platt L, Sarang A, Vlasov A, Mikhailova L, Monaghan G. Street Policing, Injecting Drug Use and Harm Reduction in a Russian City: A Qualitative Study of Police Perspectives. Journal of Urban Health. 2006; 83(5):911-925. [PubMed: 16855880]

Rhodes T, Singer M, Bourgois P, Friedman S, Strathdee S. The social structural production of HIV risk among injecting drug users. Social Science and Medicine. 2005; 61:1026-1044. [PubMed: 15955404]

Shannon K, Kerr T, Strathdee S, Shoveller J, Montaner J, Tyndall M. Prevalence and structural correlates of gender based violence among a prospective cohort of female sex workers. British Medical Journal. 2009; 339(b2939)

Shannon K, Rusch M, Shoveller J, Alexson D, Gibson K, Tyndall M. Mapping violence and policing as an environmental structural barrier to health service and syringe availability among substanceusing women in street-level sex work. International Journal of Drug Policy. 2008; 19:140-147. [PubMed: 18207725]

Small W, Kerr T, Charette J, Schechter M, Spittal P. Impacts of intensified police activity on injection drug users: Evidence from an ethnographic investigation. International Journal of Drug Policy. 2006; 17:85-95.

Small W, Rhodes T, Wood E, Kerr T. Public injection settings in Vancouver: Physical environment, social context and risk. International Journal of Drug Policy. 2007; 18:27-36. [PubMed: 17689341]

Stoltz J, Wood E, Miller C, Small W, Li K, Tyndall M, Montaner J, et al. Characteristics of young illicit drug injectors who use North America's first medically supervised safer injecting facility. Addiction Research and Theory. 2007; 15(1):63-69.

Ti L, Buxton J, Wood E, Zhang R, Montaner J, Kerr T. Difficulty accessing crack pipes and crack pipe sharing among people who use drugs in Vancouver, Canada. Substance Abuse Treatment, Prevention and Policy. 2011; 6(34)

United Nations. World Youth Report 2003. New York: United Nations; 2004.

Vancouver Sun. Conservatives must retreat on changes to bawdy-house law. Vancouver Sun; 2010 Aug 19.

Volkmann T, Lozada R, Anderson C, Patterson T, Vera A, Strathdee S. Factors associated with drugrelated harms related to policing in Tijuana, Mexico. Harm Reduction Journal. 2011; 8(7)

Werb D, Kerr T, Li K, Montaner J, Wood E. Risks Surrounding Drug Trade Involvement Among Street-Involved Youth. American Journal of Drug and Alcohol Abuse. 2008; 34:810-820. [PubMed: 19016187]

Werb D, Rowell G, Kerr T, Montaner J, Wood E. Effect of drug law enforcement on drug market violence: a systematic review. International Journal of Drug Policy. 2011; 22(2):87-94. [PubMed: 21392957]

Werb D, Wood E, Small W, Strathdee S, Li K, Montaner J, Kerr T. Effects of police confiscation of illicit drugs and syringes among injection drug users in Vancouver. International Journal of Drug Policy. 2008; 19:332-338. [PubMed: 17900888]

Wood E, Kerr T. Measuring the public health impact of police activities on illicit drug users. International Journal of Drug Policy. 2005; 16:148-149.

Wood E, Stoltz J, Montaner J, Kerr T. Evaluating methamphetamine use and risks of injection initiation among street youth: The ARYS study. Harm Reduction Journal. 2006; 3(18)

Zerbisias, A. Bawdy politics: Critics say new regulation endangers sex workers' lives. The Star; 2010 Aug 27. 
Table 1

Bivariate and multivariate GEE analysis of factors associated with being stopped, searched, or detained by police without arrest in the last six months $(n=991)$

\begin{tabular}{|c|c|c|c|c|}
\hline \multirow[b]{2}{*}{$\underline{\text { Characteristic }}$} & \multicolumn{2}{|l|}{ Unadjusted } & \multicolumn{2}{|l|}{ Adjusted } \\
\hline & Odds Ratio (95\% CI) & $p$ - value & Odds Ratio (95\% CI) & $p$ - value \\
\hline Age (per year older) & $0.99(0.81-1.21)$ & 0.92 & - & - \\
\hline Gender (male vs. female) & $1.47(1.16-1.87)$ & $<0.01$ & $1.35(1.05-1.73)$ & 0.02 \\
\hline Aboriginal ethnicity (yes vs. no) & $0.96(0.74-1.24)$ & 0.74 & - & - \\
\hline Current homelessness (yes vs. no) & $2.59(2.14-3.15)$ & $<0.01$ & $2.05(1.67-2.52)$ & $<0.01$ \\
\hline Recent incarceration * (yes vs. no) & $2.13(1.73-2.63)$ & $<0.01$ & $1.78(1.42-2.24)$ & $<0.01$ \\
\hline Daily cannabis use * (yes vs. no) & $1.59(1.24-2.04)$ & $<0.01$ & $1.31(1.02-1.68)$ & 0.04 \\
\hline Daily crack use ${ }^{*}$ (yes vs. no) & $1.72(1.44-2.04)$ & $<0.01$ & - & - \\
\hline Daily crystal meth use ${ }^{*}$ (yes vs. no) & $1.64(1.38-1.95)$ & $<0.01$ & - & - \\
\hline Daily heroin use * (yes vs. no) & $1.92(1.55-2.39)$ & $<0.01$ & $1.36(1.03-1.79)$ & 0.03 \\
\hline Overdose $^{*}$ (yes vs. no) & $1.30(1.00-1.69)$ & 0.05 & - & - \\
\hline Shared crack pipe/syringe ${ }^{*}$ (yes vs. no) & $2.20(1.84-2.63)$ & $<0.01$ & $1.61(1.33-1.95)$ & $<0.01$ \\
\hline Any injecting * (yes vs. no) & $2.02(1.67-2.45)$ & $<0.01$ & $1.37(1.07-1.76)$ & 0.02 \\
\hline Binge drug use ${ }^{*}$ (yes vs. no) & $1.57(1.33-1.87)$ & $<0.01$ & - & - \\
\hline Public drug use ${ }^{*}$ (yes vs. no) & $2.45(1.36-4.41)$ & $<0.01$ & $2.19(1.22-3.90)$ & $<0.01$ \\
\hline Sex work involvement ${ }^{*}$ (yes vs. no) & $2.02(1.50-2.73)$ & $<0.01$ & $1.67(1.20-2.33)$ & $<0.01$ \\
\hline Drug dealing * (yes vs. no) & $1.90(1.59-2.27)$ & $<0.01$ & $1.49(1.24-1.80)$ & $<0.01$ \\
\hline
\end{tabular}

GEE: generalized estimating equation

CI: confidence interval

*Activities/events in the previous 6 months 